OPEN ACCESS

Edited by:

Yinhua Lu,

Shanghai Normal University, China

Reviewed by:

Patrick Caffrey,

University College Dublin, Ireland

Haoxin Wang,

Shandong University, China

*Correspondence:

Eung-Soo Kim

eungsoo@inha.ac.kr

Specialty section:

This article was submitted to

Microbial Physiology and Metabolism,

a section of the journal

Frontiers in Microbiology

Received: 30 October 2019 Accepted: 07 January 2020

Published: 24 January 2020

Citation:

Park H-S, Kim H-J, Han C-Y,

Nah H-J, Choi S-S and Kim E-S (2020) Stimulated Biosynthesis of an

C10-Deoxy Heptaene NPP B2 via Regulatory Genes Overexpression in

Pseudonocardia autotrophica.

Front. Microbiol. 11:19.

doi: 10.3389/fmicb.2020.00019

\section{Stimulated Biosynthesis of an} C10-Deoxy Heptaene NPP B2 via Regulatory Genes Overexpression in Pseudonocardia autotrophica

\author{
Heung-Soon Park, Hye-Jin Kim, Chi-Young Han, Hee-Ju Nah, Si-Sun Choi and \\ Eung-Soo Kim*
}

Department of Biological Engineering, Inha University, Incheon, South Korea

Polyene macrolides, such as nystatin A1, amphotericin B, and NPP A1, belong to a large family of valuable antifungal polyketide compounds that are typically produced by soil actinomycetes. Previously, NPP B1, a novel NPP A1 derivative harboring a heptaene core structure, was generated by introducing two amino acid substitutions in the putative NADPH-binding motif of the enoyl reductase domain in module 5 of the NPP A1 polyketide synthase in Pseudonocardia autotrophica. This derivative showed superior antifungal activity to NPP A1. In this study, another novel derivative called NPP B2 was developed, which lacks a hydroxyl group at the $\mathrm{C} 10$ position by site-specific gene disruption of the P450 hydroxylase NppL. To stimulate the extremely low expression of the NPP B2 biosynthetic pathway genes, the 32-kb NPP-specific regulatory gene cluster was overexpressed via site-specific chromosomal integration. The extra copy of the six NPP-specific regulatory genes led to a significant increase in the NPP B2 yield from 0.19 to $7.67 \mathrm{mg} / \mathrm{L}$, which is the highest level of NPP B2 production ever achieved by the $P$. autotrophica strain. Subsequent in vitro antifungal activity and toxicity studies indicated that NPP B2 exhibited similar antifungal activity but significantly lower hemolytic toxicity than NPP B1. These results suggest that an NPP biosynthetic pathway refactoring and overexpression of its pathway-specific regulatory genes is an efficient approach to stimulating the production of an extremely low-level metabolite, such as NPP B2 in a pathway-engineered rare actinomycete strain.

Keywords: Pseudonocardia autotrophica, polyene, regulatory genes, hemolytic toxicity, antifungal activity

\section{INTRODUCTION}

More than $45 \%$ of the bioactive compounds discovered from microbial secondary metabolites are derived from actinomycetes (Bu et al., 2019). A significant number of these secondary metabolites produced by actinomycetes were utilized further as the lead compounds in the field of medicine as clinically important anticancer, antibiotic, anti-inflammatory, antiviral, antiparasitic, and antioxidant drugs (Bérdy, 2005; Subramani and Aalbersberg, 2012; Manivasagan et al., 2014; Abdelmohsen et al., 2015). Among them are polyene macrolide antibiotics, such as nystatin, 
amphotericin, candicidin, and pimaricin, which are potent antifungal compounds that are comprised typically of a polyketide core macrolactone ring with about 20-40 carbon atoms, including 3-8 conjugated double bonds (Figure 1; Caffrey et al., 2016). The major antifungal mechanism of these polyene antibiotics is believed to be the formation of ion channels via fungal ergosterol binding that mediates the leakage of cellular $\mathrm{K}^{+}$and $\mathrm{Mg}^{2+}$, which leads to the death of fungal cells (Bolard, 1986; Neumann et al., 2016).

Over the last several decades, complete polyene biosynthetic gene clusters from nystatin, amphotericin, pimaricin, and candicidin have been isolated and characterized (Aparicio et al., 1999, 2003; Zotchev et al., 2000; Caffrey et al., 2001). Polyene compounds are biosynthesized typically by a giant enzyme complex called polyketide synthase (PKS), followed by further modification of the core macrolide ring by post-PKS modification enzymes, including P450 hydroxylases and glycosyltransferases (Kim et al., 2015). Subsequent attempts to generate a range of derivatives of these antifungal polyene macrolides were pursued to enhance the antifungal activity and/or reduce their intrinsic toxicities through both semisynthetic and biosynthetic pathway refactoring approaches (Byrne et al., 2003; Nedal et al., 2007; Silveira and Husain, 2007; Caffrey et al., 2016). A heptaene version of nystatin A1 called S44HP displayed considerably higher antifungal activity than the original tetraene nystatin $\mathrm{A} 1$, which is comparable to that of amphotericin B (Bruheim et al., 2004). Mannosyl-8-deoxyamphotericins produced by inactivation of the amphL gene and introduction of the pIJ02567-nypY construct in Streptomyces nodosus exhibited lower hemolytic toxicity (Walmsley et al., 2017). In addition, highly water-soluble amphotericin B analogues were produced by the addition of extra sugar residues to amphotericin B (Caffrey et al., 2016). Recently, the discovery of C35deOAmB revealed that the antifungal activity was critical for binding to ergosterol, not for ion-channel formation (Gray et al., 2012), which generated toxicity-reduced amphotericin B derivatives (Cioffi et al., 2015; Muraglia et al., 2019). Overall, the engineering of polyene PKS to change the number of conjugated double bonds as well as post-PKS modifications for manipulation of the sugar and hydroxyl moieties is considered an important strategy for the generation of pharmacokinetically improved novel polyene derivatives (Bruheim et al., 2004; Gray et al., 2012; Caffrey et al., 2016; Walmsley et al., 2017; Muraglia et al., 2019).

NPP A1 is a disaccharide-containing polyene antifungal compound produced by a rare actinomycete, Pseudonocardia autotrophica, with an identical core macrolactone structure to nystatin A1 except for an additional $\mathrm{N}$-acetyl-glucosamine (Figure 1; Lee et al., 2012). In the NPP A1 biosynthesis process, the macrolide backbone is synthesized by six type I PKSs, and the unique di-sugar moiety, mycosaminyl-( $\alpha 1-4)-N$-acetylglucosamine, is then attached by two glycosyltransferasesencoding $n p p D I$ and $n p p Y$ and finally hydroxylated by $\mathrm{P} 450$ hydroxylase-encoding $n p p L$ (Kim et al., 2015). In terms of the biological activities, this polyene has superior water solubility and reduced hemolytic toxicity but shows slightly lower antifungal activity than nystatin A1 (Lee et al., 2012). Elucidation of the post-PKS modification steps of NPP A1 biosynthesis in
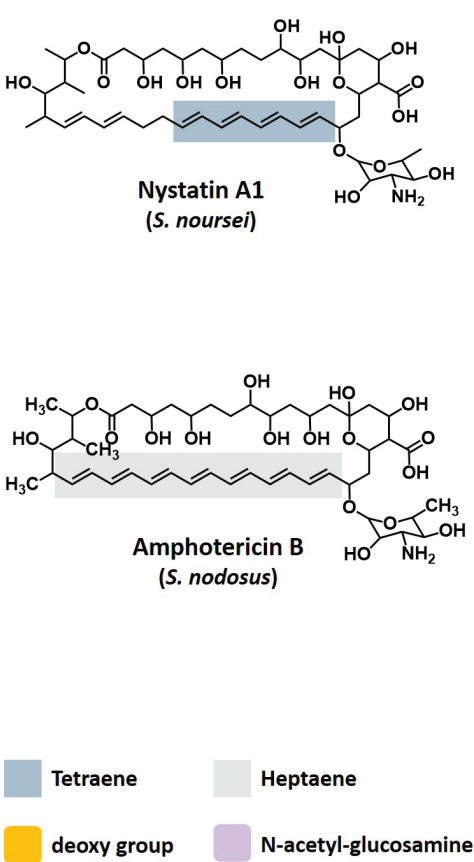
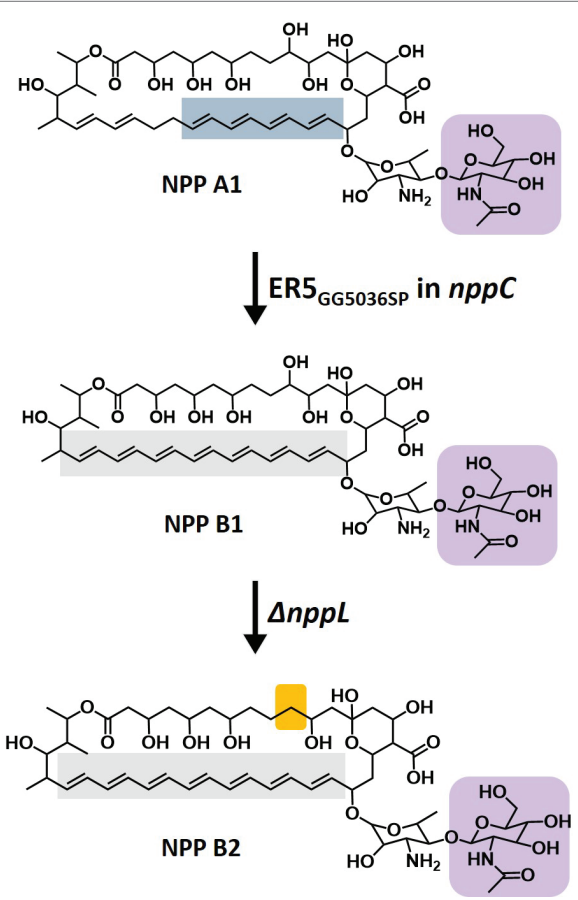

FIGURE 1 | Structure of polyene macrolides. Nystatin A1, a typical tetraene polyene macrolide produced by Streptomyces noursei. Amphotericin B, the most potent polyene macrolide produced by Streptomyces nodosus. Nystatin-like Pseudonocardia polyene (NPP) A1, a disaccharide-containing tetraene polyene macrolide produced by Pseudonocardia autotrophica. NPP B1, a disaccharide-containing heptaene polyene macrolide produced by P. autotrophica ER5 GG5036sP mutant. NPP B2 C10-deoxy NPP B1 produced by inactivation of the $n p p L$ gene in P. autotrophica ER5 Ga5036sP mutant. 
P. autotrophica highlighted the potential to develop novel NPP A1 derivatives (Kim et al., 2015). Several studies were conducted to develop NPP A1 derivatives to enhance the antifungal activity, resulting in two analogues, NPP A2 and NPP B1. NPP A2 lacks a $\mathrm{C} 10$ hydroxyl group that was generated by the inactivation of the P450 hydroxylase-encoding $n p p L$ gene in $P$. autotrophica (Kim et al., 2016). NPP B1 was generated by changing its core macrolactone structure from tetraene to heptaene through site-specific, two amino acid substitutions in the putative NADPH-binding motif of the enoyl reductase domain in module 5 of the NPP A1 polyketide synthase NppC (Figure 1; Kim et al., 2018). Interestingly, both NPP A2 and NPP B1 exhibited higher antifungal activities than those of NPP A1.

In this study, another NPP A1 analogue called NPP B2 was developed, which was generated by the inactivation of the polyketide enoyl reductase (ER) domain in the fifth module as well as the P450 hydroxylase-encoding nppL gene in the NPP A1 producing P. autotrophica strain (Figure 1). To overcome the extremely low level of NPP B2 production because of its pathway refactoring, the $32-\mathrm{kb}$ NPP-specific regulatory gene cluster was overexpressed in the NPP B2 production strain, followed by isolation and characterization of the biological activities of NPP B2.

\section{MATERIALS AND METHODS}

\section{Strains and Growth Conditions}

P. autotrophica KCTC9441 purchased from the Korean Collection for Type Cultures was used for NPP production. The strain was grown routinely in ISP2 agar (malt extract $10 \mathrm{~g}$, yeast extract $4 \mathrm{~g}$, glucose $4 \mathrm{~g}$, and agar $20 \mathrm{~g} / \mathrm{L}$ ) at $28^{\circ} \mathrm{C}$ for the sporulation and seed culture. YEME medium (yeast extract $3 \mathrm{~g}$, peptone $5 \mathrm{~g}$, malt extract $3 \mathrm{~g}$, glucose $10 \mathrm{~g}$, sucrose $340 \mathrm{~g} / \mathrm{L}$, and $5 \mathrm{mM} \mathrm{MgCl}_{2}$ ) was used to produce the NPP derivatives (Lee et al., 2012). Candida albicans ATCC 14053 was grown on YM medium (dextrose $10 \mathrm{~g}$, peptone $5 \mathrm{~g}$, yeast extract $3 \mathrm{~g}$, Malt extract $3 \mathrm{~g}$, and agar $20 \mathrm{~g} / \mathrm{L}$ ) at $30^{\circ} \mathrm{C}$ for $24 \mathrm{~h}$. All Escherichia coli strains were incubated at $37^{\circ} \mathrm{C}$ in Luria-Bertani medium supplemented with the appropriate antibiotics where needed.

\section{Inactivation of $\mathrm{NppL}$ and Overexpression of NPP-Specific Regulatory Gene Cluster}

A $n p p L$ gene inactivation cassette, including the upstream and downstream regions, was constructed by PCR amplification using the following primer pairs: upstream region, DELL_1F (5'-GAATTCCGTCCTGTACTCGTCGGT-3') and DELL_1R (5'-CTGCAGTCA TGACGCGTCCTCCGT-3') and downstream region, DELL_2F (5'-CTGCAGAC GCGGTCACGATGGCGC-3') and DELL_2R (5'-AAGCTTACCTGGCCGAGCAGATGG-3') (Kim et al., 2015). The amplified fragments were digested with HindIII-EcoRI and ligated into pKC1132. The recombinants were selected on LB medium containing apramycin. The $n p p L$ gene-inactivation plasmid was introduced into the chromosome of the NPP B1 production strain, P. autotrophica ER5 mutant.
To overexpress the NPP-specific regulatory genes, the previously constructed pNPPREG, encompassing the $32-\mathrm{kb}$ NPP-specific regulatory gene cluster, was integrated into the chromosome of the B2 production strain (Han et al., 2019). The recombination conjugants were selected on ISP2 medium containing apramycin.

\section{Production and Purification of NPP Derivatives}

NPP or its derivative production strains were inoculated in $300 \mathrm{ml}$ of ISP2 medium containing the appropriate antibiotics at $30^{\circ} \mathrm{C}$ and $220 \mathrm{rpm}$ for $72 \mathrm{~h}$. The pre-cultures were added to $3 \mathrm{~L}$ YEME medium in a $5 \mathrm{~L}$ bioreactor for batch fermentation. After $48 \mathrm{~h}$ of cultivation, $150 \mathrm{~g}$ of Amberlite XAD16 resin (Sigma-Aldrich, USA) was added to the culture broth. After $24 \mathrm{~h}$ of resin addition, the mycelia and resin from the culture broth were separated and then extracted twice in $600 \mathrm{ml}$ of $n$-butanol. The extract was concentrated using a vacuum evaporator, after which the concentrated extract was dissolved in methanol and loaded onto a column packed with a C18 reversed-phase silica gel (Daiso, Japan) along with methanolwater $(30: 70, \mathrm{v} / \mathrm{v})$ to remove any residual sugar from the production media. The extracts with sugar removed were purified using a fraction collector (Interchim, France) on a gradient consisted of solvents A (water) and B (methanol): 30\% B (v/v) $(0-10 \mathrm{~min})$ and $100 \% \mathrm{~B}(\mathrm{v} / \mathrm{v})(100 \mathrm{~min})$ at a flow rate of $20 \mathrm{ml} / \mathrm{min}$. The fractions containing NPP or its derivatives with $>80 \%$ purity were detected at $405 \mathrm{~nm}$ and analyzed by high performance liquid chromatography (HPLC). The column was equilibrated with $50 \%$ solvent $\mathrm{A}(0.05 \mathrm{M}$ ammonium acetate, $\mathrm{pH} 6.5$ ) and $50 \%$ solvent $\mathrm{B}$ (methanol); the flow rate was set to $1.0 \mathrm{ml} / \mathrm{min}$ using the following conditions: $0-3 \mathrm{~min}$, $50-75 \% \mathrm{~B} ; 3-30 \mathrm{~min}, 75-100 \% \mathrm{~B}$; 30-33 $\mathrm{min}, 100-50 \% \mathrm{~B}$; and 33-40 $\mathrm{min}, 50 \% \mathrm{~B}$ (Won et al., 2017).

\section{Liquid Chromatography-Mass Spectrometry/Mass Spectrometry Analysis} NPP B2 showing $>80 \%$ purity was analyzed using A Triple TOF $5600+($ AB Sciex, USA) coupled with Ultimate 3000 (Thermo Scientific, USA). Mass spectrometry was operated in both positive and negative ion modes over a mass range from 50 to $2,000 \mathrm{~m} / z$ using an electrospray ionization source. The settings were nitrogen gas for nebulization at 50 psi, heater gas pressure at $50 \mathrm{psi}$, curtain gas at $25 \mathrm{psi}$, temperature of $500^{\circ} \mathrm{C}$, and an ion spray voltage at $5,500 \mathrm{~V}$ in positive ion mode and $-4,500 \mathrm{~V}$ in negative ion mode. The optimized declustering potential (DP) and collision energy (CE) were set to 60 and $10 \mathrm{eV}$ in positive ion mode, and to -60 and $-10 \mathrm{eV}$ in negative ion mode, respectively. A sweeping collision energy setting at $35 /-35 \pm 15 \mathrm{eV}$ was applied for collisioninduced dissociation (CID). Chromatographic conditions: solution A ( $0.1 \%$ formic acid in distilled water) and solution B $(0.1 \%$ formic acid in acetonitrile) were used for elution and loaded onto Phenomenex Kinetex $1.7 \mu \mathrm{C} 18(2.1 \mathrm{~mm} \times$ $150 \mathrm{~mm}, 1.7 \mu \mathrm{m})$. The flow rate was set to $0.4 \mathrm{ml} / \mathrm{min}$ using the following conditions: $0-1 \mathrm{~min}, 90 \% \mathrm{~A} ; 1-5 \mathrm{~min}, 90-50 \%$ 
A; 5-18 min, 50-0\% A; 18-25 min, 0\% A; 25-27 min, 0-90\% $\mathrm{A}$; and $27-30 \mathrm{~min}, 90 \% \mathrm{~A}$.

\section{RNA Analysis by Quantitative Real-Time Polymerase Chain Reaction}

RNA was prepared using the RNeasy Mini Kit (Qiagen, Germany). cDNA conversion was carried out using a PrimeScript $1^{\mathrm{ST}}$ strand cDNA Synthesis Kit (TaKaRa, Japan) according to the manufacturer's instructions. Real-time PCR was performed using TaKaRa SYBR Premix Ex Taq (Perfect Real Time) with a Thermal Cycler Dice Real Time System Single (code TP850; TaKaRa, Japan). Supplementary Table S1 lists the primer pairs. The PCR conditions included activation for $10 \mathrm{~min}$ at $95^{\circ} \mathrm{C}$, followed by 35 cycles of $30 \mathrm{~s}$ at $95^{\circ} \mathrm{C}, 30 \mathrm{~s}$ at $58^{\circ} \mathrm{C}$, and $30 \mathrm{~s}$ at $72^{\circ} \mathrm{C}$. The data were collected during each $72^{\circ} \mathrm{C}$ step, and melting curve analysis was performed at default settings ranging from 60 to $95^{\circ} \mathrm{C}$. The relative level of amplified mRNA was normalized to the mRNA expression level of the housekeeping gene, $P$. autotrophica hrdB, which was amplified as an internal control using the primer pairs $h r d B \_F\left(5^{\prime}\right.$-GCGGTGGAGA AGTTCGACTA-3') and $h r d B \_R$ (5'-TTGATGACCTCGACCATGTG-3') (Han et al., 2019).

\section{In vitro Assays for Biological Activities}

For in vitro antifungal assay, we adapted to the Clinical and Laboratory Standards Institute document M27-A3 (Wayne, 2008). After C. albicans was cultured in YM medium at $30^{\circ} \mathrm{C}$ for $24 \mathrm{~h}$, the cultured solution was diluted with YM medium until the $\mathrm{OD}$ value is 0.3 at $530 \mathrm{~nm}$. A working suspension was made by a 1:2,000 dilution with RPMI-1640 broth media (with glutamine and phenol red, without bicarbonate, Sigma-Aldrich, USA), which resulted in $5.0 \times 10^{2}$ to $2.5 \times 10^{3}$ cells per $\mu \mathrm{l}$. Ten microliters of the DMSO containing polyene antibiotics at various concentrations $(3.125-1600 \mu \mathrm{g} / \mathrm{ml})$ were added to the working suspension of $990 \mu \mathrm{l}$, and then, the mixtures were incubated at $30^{\circ} \mathrm{C}$ without shaking for $48 \mathrm{~h}$. The colorimetric change of the mixture from red to yellow indicated the growth of C. albicans. The minimum inhibitory concentration (MIC) values were determined by measuring the minimum concentration that changed color to yellow. The experiment was performed in the duplicate.

For in vitro hemolysis assay, we adapted from a previously reported method (Nedal et al., 2007). Briefly, defibrinated horse blood was purchased from Kisan Biotech (South Korea). The polyene compounds were then prepared to the following concentrations with DMSO: 1-200 $\mu \mathrm{g} / \mathrm{ml}$. A $50 \mu \mathrm{l}$ of each polyene solution was added to $450 \mu \mathrm{l}$ of $2.5 \%$ defibrinated horse blood buffered with RBC buffer (10 mM NaH $\mathrm{PO}_{4}$, $150 \mathrm{mM} \mathrm{NaCl}, 1 \mathrm{mM} \mathrm{MgCl}_{2}$, and $\mathrm{pH} \mathrm{7.4),} \mathrm{which} \mathrm{resulted}$ in a 1:10 dilution of each concentration of polyene. The samples were then incubated at $37^{\circ} \mathrm{C}$ for $30 \mathrm{~min}$. After incubation, the samples were centrifuged at $10,000 \times g$ for $2 \mathrm{~min}$. Next, $100 \mu \mathrm{l}$ of the supernatant from each sample was added to a 96-well plate, after which the absorbance was read at $540 \mathrm{~nm}$ using a microplate reader (TECAN, Switzerland). The percentage hemolysis of each sample was defined as $\left(\mathrm{Abs}_{\text {sample }}-\mathrm{Abs}_{\text {negative }} / \mathrm{Abs}_{\text {positive }}-\mathrm{Abs}_{\text {negative }}\right) \times 100$ (\%) to calculate the minimum hemolysis concentration (MHC). The positive hemolysis sample was prepared by adding defibrinated horse blood $11.25 \mu \mathrm{l}$ and DMSO $50 \mu \mathrm{l}$ to distilled water $438.75 \mu \mathrm{l}$, and the negative hemolysis sample was prepared by adding defibrinated horse blood $11.25 \mu \mathrm{l}$ and DMSO $50 \mu \mathrm{l}$ to RBC buffer $438.75 \mu \mathrm{l}$.

\section{RESULTS}

\section{Construction of the NPP B2 Production Strain}

An in vitro antifungal assay confirmed that the NPP B1, a heptaene version of NPP A1, showed much higher antifungal activity than the tetraene NPP A1 (Kim et al., 2018). Therefore, we tried to generate pharmacokinetically improved heptaene NPP B1 derivative through the engineering of post-PKS modification. Based on the previous results that characterization of the P450 hydroxylases, which were a region-specific hydroxylation such as AmphL (amphotericin), NysL (nystatin), and NppL (NPP) (Byrne et al., 2003; Volokhan et al., 2006; Kim et al., 2016), the NPP B1 production strain was engineered by inactivation of the $n p p L$ gene, which was involved in NPP C10 region-specific hydroxylation (Figures 2A,B; Supplementary Figure S1). Inactivation of the $n p p L$ gene was performed successfully by homologous recombination using the $\mathrm{pKC1132}$ Streptomyces suicide vector system, and the mutation was verified genetically by PCR product sequencing analysis (Figure 2C; Supplementary Figure S2). LC-MS analysis of purified NPP B2 contained a signal at $m / z 1111.5807$ for $\left[\mathrm{C}_{53} \mathrm{H}_{85} \mathrm{~N}_{2} \mathrm{O}_{22}\right]^{+}$ (calculated mass of NPP B2 is 1110.57) confirming that NPP B2 had been produced, as expected in the constructed mutant strain (Supplementary Figure S3).

\section{Stimulation of NPP B2 Production Through Overexpression of the NPP Pathway-Specific Regulatory Genes}

Although the NPP B2 production strain was developed successfully by inactivation of the ER domain of module 5 followed by the $\mathrm{P} 450$ hydroxylase-encoding $n p p L$ gene from the NPP A1 production strain, the NPP B2 production level was reduced approximately 40 -fold to $0.2 \mathrm{mg} / \mathrm{L}$ compared to the NPP A1 production level in the P. autotrophica wild type. Among the attempts to increase the production of NPP derivatives, a strategy was conducted to increase the production level of NPP B2 through overexpression of the NPP pathwayspecific regulatory genes. In previous studies, pNPPREG was constructed by cloning a $32-\mathrm{kb}$ right-hand portion of $\mathrm{BGC}$ containing the six NPP-specific regulatory genes (nppRI-nppRVI) into a Streptomyces artificial chromosomal vector pSBAC (Han et al., 2019). To stimulate NPP B2 production, pNPPREG containing the entire regulatory genes was integrated into the chromosome of the NPP B2 production strain (Figure 3A). As a result, the level of NPP B2 production was increased significantly (approximately 39-fold to $7.67 \mathrm{mg} / \mathrm{L}$ ) (Figure 3B). 


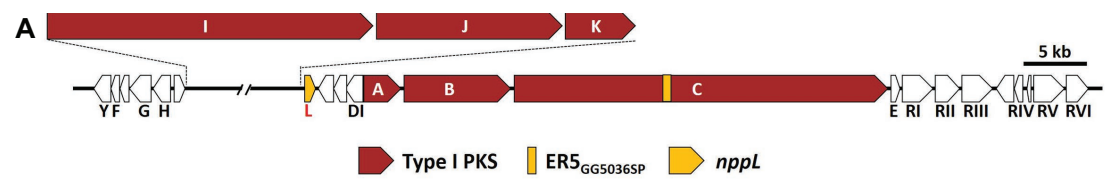

B

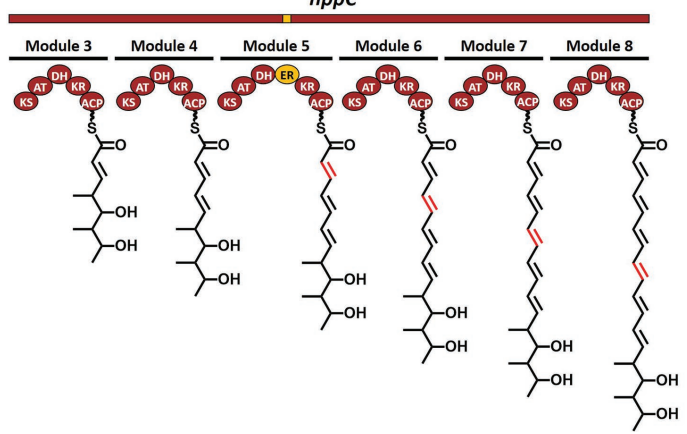

(C)

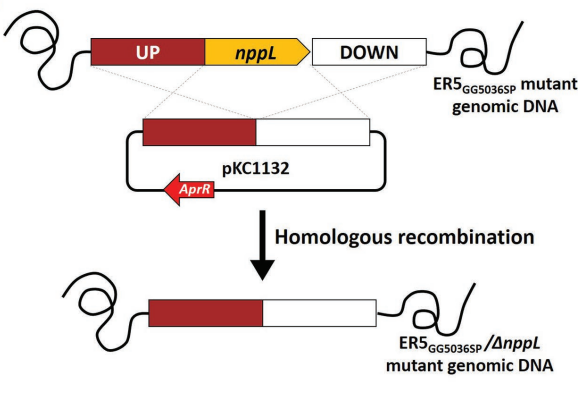

FIGURE 2 | (A) Development of NPP B2 production strains in P. autotrophica. (B) Organization of modular polyketide synthases involved in mutated NppC by inactivation of enoyl reductase domain in module 5 (ER5). ACP, acyl carrier protein; AT, acyl-transferase; KS, ketosynthase; KR, ketoreductase; DH, dehydratase; ER, enoyl reductase. (C) Inactivation scheme of $n p p L$ gene in NPP B1 production strain (ER5 domain mutant).

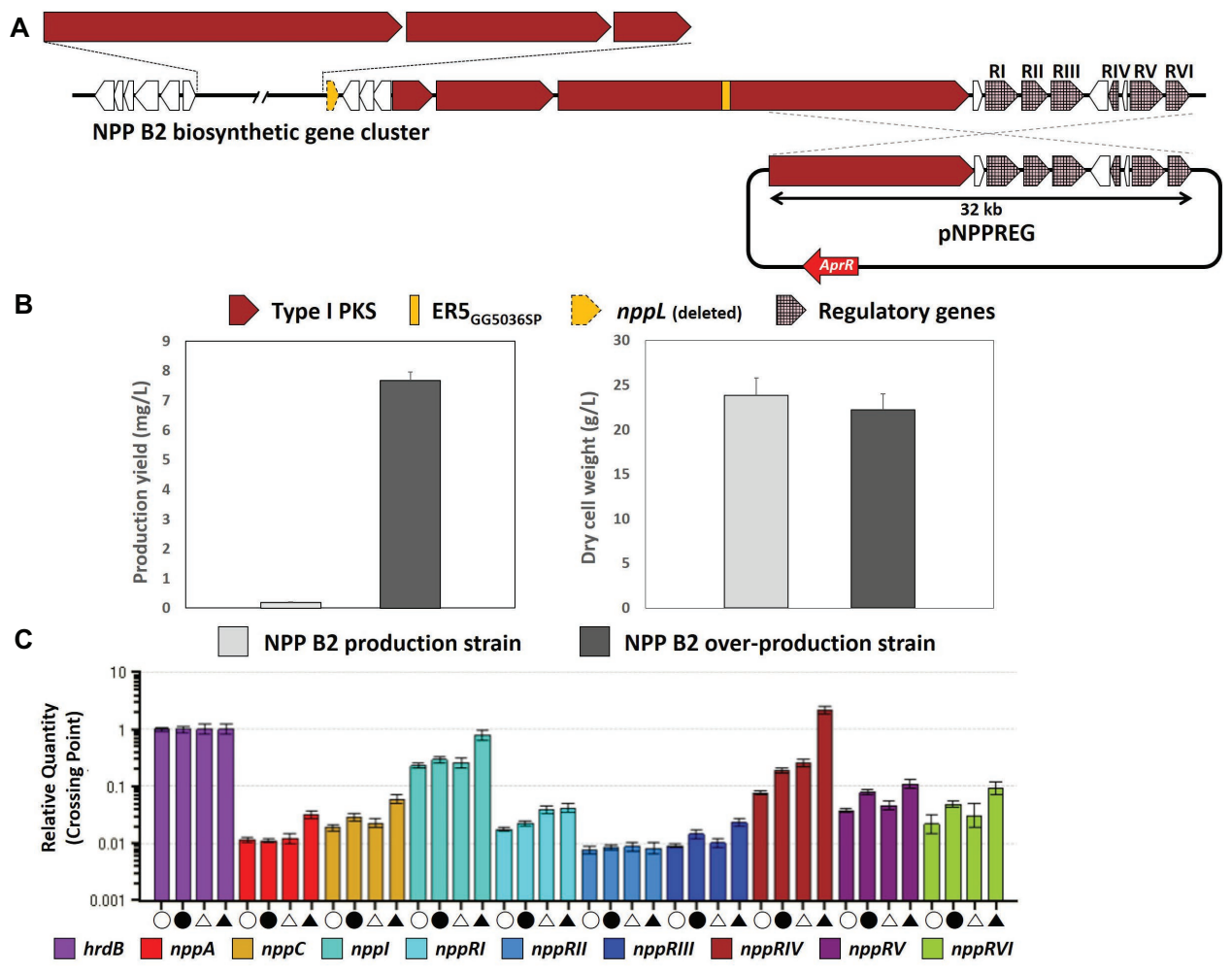

FIGURE 3 | (A) Overexpression scheme of NPP-specific regulatory gene cluster in NPP B2 production strain. (B) Comparison of NPP B2 production yields with newly constructed NPP B2 over-production strain after $72 \mathrm{~h}$ culture. (C) Transcript analysis of NPP B2 production strains by qRT-PCR. Open circle, transcripts from the NPP B2 production strain at $24 \mathrm{~h}$; closed circle, transcripts from the NPP B2 production strain at $48 \mathrm{~h}$; open triangle, transcripts from the NPP B2 over-production mutant at $24 \mathrm{~h}$; closed triangle, transcripts from the NPP B2 over-production mutant at 48 h; house-keeping gene, hrdB (light purple); PKS genes, $n p p A$ (red), nppC (yellow), and nppl (emerald green); regulatory genes related to NPP B2 biosynthesis, nppRI (sky blue), nppRIl (blue), nppRIII (dark blue), nppRIV (brown), nppRV (dark purple), and nppRVI (light green). All transcript measurements were performed in duplicate. 
The transcription levels of the NPP B2 biosynthetic genes were analyzed to further understand the molecular basis responsible for enhanced NPP B2 production in the engineered NPP B2 over-production strain. qRT-PCR analysis revealed increased transcription of the PKS genes, such as $n p p A$ and $n p p C$, in the NPP B2 over-production strain compared to the parental strain (Figure 3C). As expected, the transcription levels of all five NPP-pathway specific regulatory genes, except $n p p R I I$, were also stimulated (Figure $3 \mathrm{C}$ ), suggesting that the enhanced transcription level of the refactored NPP B2 biosynthetic pathway genes is critical for the titer improvement.

\section{In vitro Antifungal Activity and Hemolytic Toxicity}

Based on successful NPP B2 yield improvement, the purified NPP B2 was evaluated for both in vitro antifungal activity and the hemolytic toxicity. Minimum inhibitory concentration (MIC) evaluation assays of in vitro antifungal activity using the colorimetric change in the RPMI-1640 media containing C. albicans were employed (Wayne, 2008). The MIC value of NPP B2 against C. albicans $(1.0 \mu \mathrm{g} / \mathrm{ml})$ was slightly higher than amphotericin B $(0.25 \mu \mathrm{g} / \mathrm{ml})$ and NPP B1 $(0.5 \mu \mathrm{g} / \mathrm{ml})$ (Table 1; Supplementary Figure S4). Interestingly, however, in vitro hemolytic toxicity evaluation, NPP B2 exhibited much reduced hemolytic toxicity than its parental NPP B1. The minimum hemolytic concentration (MHC) value for NPP B2 was measured as $80.18 \mu \mathrm{g} / \mathrm{ml}$, whereas the MHC value of amphotericin B was $3.26 \mu \mathrm{g} / \mathrm{ml}$ under the conditions tested, indicating that the in vitro toxicity of NPP B2 was approximately 25-fold lower than that of amphotericin B (Table 1; Supplementary Figure S5). Moreover, the in vitro toxicity was 4.5 -fold lower than the MHC value of NPP B1 $(17.72 \mu \mathrm{g} / \mathrm{ml})$. These results suggest that the absence of the hydroxyl moiety at the C10 position of NPP B2 could play an important role in controlling both antifungal acidity and hemolytic toxicity.

\section{DISCUSSION}

The genome mining approach of rare actinomycetes followed by the activation of its cryptic biosynthetic gene cluster (BGC) has

TABLE 1 | In vitro antifungal activity and toxicity of polyene macrolides.

\begin{tabular}{|c|c|c|c|}
\hline & Amphotericin B & NPP B1 & NPP B2 \\
\hline \multicolumn{4}{|c|}{ Antifungal activity (MIC, $\mu \mathrm{g} / \mathrm{ml})^{\mathrm{a}}$} \\
\hline $\begin{array}{l}\text { Candida albicans } \\
\text { ATCC } 14053\end{array}$ & 0.25 & 0.5 & 1.0 \\
\hline \multicolumn{4}{|c|}{ Hemolytic toxicity (MHC, $\mu \mathrm{g} / \mathrm{ml})^{\mathrm{b}}$} \\
\hline & $3.26 \pm 0.259$ & $\begin{array}{c}17.71 \pm 1.235 \\
(5.4 \text {-fold })\end{array}$ & $\begin{array}{c}80.18 \pm 1.168 \\
(25 \text {-fold })\end{array}$ \\
\hline
\end{tabular}

${ }^{a} \mathrm{MIC}$, minimum inhibitory concentration (values resulting in no visible growth of C. albicans).

${ }^{b} \mathrm{MHC}$, minimum hemolytic concentration (values causing $90 \%$ hemolysis against horse blood cells \pm percentage standard deviation). become an attractive strategy to screen and develop novel bioactive compounds (Choi et al., 2018). The P. autotrophica strain described here was classified originally as a polyene non-production strain, which was later proven to be a producer of a novel di-saccharidecontaining NPP A1 through culture optimization and whole genome sequencing (Lee et al., 2012). Although an NPP A1 BGC refactoring strategy generated a C10-deoxy NPP A1 (named NPP A2) and a heptaene version of NPP A1 (named NPP B1), their extremely low titers were major hurdles for further characterization of their biological activities.

Previously, several strategies, including overexpression of the pathway-specific regulatory gene, deletion of the global antibiotic downregulator, in situ screening of random mutants, co-culture system, and cultivation with xenobiotics, all failed to improve NPP B1 production (Kim et al., 2018). Recently, the entire cluster containing all six NPP pathway-specific genes in a pSBAC system followed by its re-integration into the P. autotrophica chromosome led to a significant increase in the NPP B1 titer (Han et al., 2019).

In this study, another novel derivative, called the NPP B2 production strain, was first generated by site-specific inactivation of the $n p p L$ gene in the NPP B1 production of the $P$. autotrophica mutant strain. C10-deoxy NPP B1 (NPP B2) was also generated based on a previous report that the C8-deoxy amphotericin produced by the inactivation of amphL in $S$. nodosus and C10-deoxy nystatin by the inactivation of nysL in Streptomyces noursei (Byrne et al., 2003; Volokhan et al., 2006). Owing to the extremely low titer of NPP B2, however, its biological characterization could not be pursued without strain improvement. Through the chromosomal integration of all six NPP pathwayspecific genes in the NPP B2 production strain, its titer was improved significantly (approximately 39 -fold), which was sufficient to proceed for further biological assays, including antifungal and hemolytic toxicity assays.

This paper described for the first time the in vitro biological activities of NPP B2, a novel heptaene version of the NPP derivative. Although the in vitro antifungal activity of NPP B2 was higher than that of tetraene-type polyenes, such as nystatin A1, NPP A1, and A2, it showed slightly lower antifungal activity than other heptaene-type polyenes, including amphotericin B and NPP B1. Interestingly, the in vitro hemolytic activity of NPP B2 was approximately 25 times lower than those of amphotericin B and NPP B1, suggesting that the hydroxyl moiety at the C10 position of NPP could play a critical role in controlling both the antifungal activity and the hemolytic toxicity, probably by affecting its binding affinity to cholesterol and ergosterol. Overall, these results suggest that the combination of rational BGC refactoring and its genetic strain improvement approach is an efficient strategy to stimulate the production of an extremely low-level metabolite, such as NPP B2 in a rare actinomycetes strain.

\section{DATA AVAILABILITY STATEMENT}

The datasets generated for this study can be found in the EU108007. 


\section{AUTHOR CONTRIBUTIONS}

H-SP, S-SC, and E-SK designed the experiments. H-SP, H-JK, and $\mathrm{C}-\mathrm{YH}$ performed the experiments. H-SP, H-JN, and E-SK wrote the manuscript.

\section{FUNDING}

This study was supported by Agricultural Microbiome R\&D Program, Ministry of Agriculture, Food and Rural Affairs,

\section{REFERENCES}

Abdelmohsen, U. R., Grkovic, T., Balasubramanian, S., Kamel, M. S., Quinn, R. J., and Hentschel, U. (2015). Elicitation of secondary metabolism in actinomycetes. Biotechnol. Adv. 33, 798-811. doi: 10.1016/j.biotechadv. 2015.06.003

Aparicio, J. F., Caffrey, P., Gil, J. A., and Zotchev, S. B. (2003). Polyene antibiotic biosynthesis gene clusters. Appl. Microbiol. Biotechnol. 61, 179-188. doi: 10.1007/s00253-002-1183-5

Aparicio, J. F., Colina, A. J., Ceballos, E., and Martín, J. F. (1999). The biosynthetic gene cluster for the 26-membered ring polyene macrolide pimaricin. J. Biol. Chem. 274, 10133-10139. doi: 10.1074/jbc.274.15.10133

Bérdy, J. (2005). Bioactive microbial metabolites: a personal view. J. Antibiot. 58, 1-26. doi: 10.1038/ja.2005.1

Bolard, J. (1986). How do the polyene macrolide antibiotics affect the cellular membrane properties? Biochim. Biophys. Acta Rev. Biomembr. 864, 257-304. doi: 10.1016/0304-4157(86)90002-X

Bruheim, P., Borgos, S. E., Tsan, P., Sellta, H., Ellingsen, T. E., Lancelin, J. M., et al. (2004). Chemical diversity of polyene macrolides produced by Streptomyces noursei ATCC11455 and recombinant strain ERD44 with genetically altered polyketide synthase NysC. Antimicrob. Agents Chemother. 48, 4120-4129. doi: 10.1128/AAC.48.11.4120-4129.2004

Bu, Q. T., Yu, P., Wang, J., Li, Z. Y., Chen, X. A., and Mao, X. M. (2019). Rational construction of genome-reduced and high-efficient industrial Streptomyces chassis based on multiple comparative genomic approaches. Microb. Cell Factories 18:16. doi: 10.1186/s12934-019-1055-7

Byrne, B., Carmody, M., Gibson, E., Rawlings, B., and Caffrey, P. (2003). Biosynthesis of deoxyamphotericins and deoxyamphoteronolides by engineered strains of Streptomyces nodosus. Chem. Biol. 10, 1215-1224. doi: 10.1016/j. chembiol.2003.12.001

Caffrey, P., De Poire, E., Sheehan, J., and Sweeney, P. (2016). Polyene macrolide biosynthesis in streptomycetes and related bacteria: recent advances from genome sequencing and experimental studies. Appl. Microbiol. Biotechnol. 100, 3893-3908. doi: 10.1007/s00253-016-7474-z

Caffrey, P., Lynch, S., Flood, E., Finnan, S., and Oliynyk, M. (2001). Amphotericin biosynthesis in Streptomyces nodosus deductions from analysis of polyketide synthase and late genes. Chem. Biol. 8, 713-723. doi: 10.1016/ S1074-5521(01)00046-1

Choi, S. S., Katsuyama, Y., Bai, L., Deng, Z., Ohnishi, Y., and Kim, E. S. (2018). Genome engineering for microbial natural product discovery. Curr. Opin. Microbiol. 45, 53-60. doi: 10.1016/j.mib.2018.02.007

Cioffi, A. G., Hou, J., Grillo, A. S., Diaz, K. A., and Burke, M. D. (2015). Restored physiology in protein-deficient yeast by a small molecule channel. J. Am. Chem. Soc. 137, 10096-10099. doi: 10.1021/jacs.5b05765

Gray, K. C., Palacios, D. S., Dailey, I., Endo, M. M., Uno, B. E., Wilcock, B. C., et al. (2012). Amphotericin primarily kills yeast by simply binding ergosterol. Proc. Natl. Acad. Sci. USA 109, 2234-2239. doi: 10.1073/ pnas.1117280109

Han, C. Y., Jang, J. Y., Kim, H. J., Choi, S. S., and Kim, E. S. (2019). Pseudonocardia strain improvement for stimulation of the di-sugar heptaene Nystatin-like Pseudonocardia polyene B1 biosynthesis. J. Ind. Microbiol. Biotechnol. 46, 649-655. doi: 10.1007/s10295-019-02149-7
Republic of Korea [as part of the (multi-ministerial) Genome Technology to Business Translation Program] No. 918008-04. This work was also funded by National Research Foundation of Korea (NRF) (Project No. NRF-2017R1A2A2A05069859).

\section{SUPPLEMENTARY MATERIAL}

The Supplementary Material for this article can be found online at: https://www.frontiersin.org/articles/10.3389/fmicb.2020.00019/ full\#supplementary-material

Kim, H. J., Han, C. Y., Park, J. S., Oh, S. H., Kang, S. H., Choi, S. S., et al. (2018). Nystatin-like Pseudonocardia polyene B1, a novel disaccharidecontaining antifungal heptaene antibiotic. Sci. Rep. 8:13584. doi: 10.1038/ s41598-018-31801-y

Kim, H. J., Kim, M. K., Lee, M. J., Won, H. J., Choi, S. S., and Kim, E. S. (2015). Post-PKS tailoring steps of a disaccharide-containing polyene NPP in Pseudonocardia autotrophica. PLoS One 7:10. doi: 10.1371/journal.pone.0123270

Kim, M. K., Won, H. J., Kim, H. J., Choi, S. S., Lee, H. S., Kim, P., et al. (2016). Carboxyl-terminal domain characterization of polyene specific P450 hydroxylase in Pseudonocardia autotrophica. J. Ind. Microbiol. Biotechnol. 43, 1625-1630. doi: 10.1007/s10295-016-1813-z

Lee, M. J., Kong, D., Han, K., Sherman, D. H., Bai, L., Deng, Z., et al. (2012). Structural analysis and biosynthetic engineering of a solubility-improved and less-hemolytic nystatin-like polyene in Pseudonocardia autotrophica. Appl. Microbiol. Biotechnol. 95, 157-168. doi: 10.1007/s00253-012-3955-x

Manivasagan, P., Venkatesan, J., Sivakumar, K., and Kim, S. K. (2014). Pharmaceutically active secondary metabolites of marine actinobacteria. Microbiol. Res. 169, 262-278. doi: 10.1016/j.micres.2013.07.014

Muraglia, K. A., Chorghade, R. S., Kim, B. R., Tang, X. X., Shah, V. S., Grillo, A. S., et al. (2019). Small-molecule ion channels increase host defences in cystic fibrosis airway epithelia. Nature 567, 405-408. doi: 10.1038/ s41586-019-1018-5

Nedal, A., Sletta, H., Brautaset, T., Borgos, S. E., Sekurova, O. N., Ellingsen, T. E., et al. (2007). Analysis of the mycosamine biosynthesis and attachment genes in the nystatin biosynthetic gene cluster of Streptomyces noursei ATCC 11455. Appl. Microbiol. Biotechnol. 73, 7400-7407. doi: 10.1128/AEM.01122-07

Neumann, A., Wieczor, M., Zielinska, J., Baginski, M., and Czub, J. (2016). Membrane sterols modulate the binding mode of amphotericin B without affecting its affinity for a lipid bilayer. Langmuir 32, 3452-3461. doi: 10.1021/ acs.langmuir.5b04433

Silveira, F. P., and Husain, S. (2007). Fungal infections in solid organ transplantation. Med. Mycol. 45, 305-320. doi: 10.1080/13693780701200372

Subramani, R., and Aalbersberg, W. (2012). Marine actinomycetes an ongoing source of novel bioactive metabolites. Microbiol. Res. 167, 571-580. doi: 10.1016/j.micres.2012.06.005

Volokhan, O., Sletta, H., Ellingsen, T. E., and Zotchev, S. B. (2006). Characterization of the P450 monooxygenase NysL, responsible for C-10 hydroxylation during biosynthesis of the polyene macrolide antibiotic nystatin in Streptomyces noursei. Appl. Environ. Microbiol. 72, 2514-2519. doi: 10.1128/AEM.72. 4.2514-2519.2006

Walmsley, S., De Poire, E., Rawlings, B., and Caffrey, P. (2017). Engineered biosynthesis and characterization of disaccharide-modified 8-deoxyamphoteronlides. Appl. Microbiol. Biotechnol. 101, 1899-1905. doi: 10.1007/s00253-016-7986-6

Wayne, P. A. (2008). Reference for broth dilution antifungal susceptibility testing of yeasts; approved standard. 3rd Edn. Clinical and Laboratory Standards Institute document, M27-A3.

Won, H. J., Kim, H. J., Jang, J. Y., Kang, S. H., Choi, S. S., and Kim, E. S. (2017). Improved recovery and biological activities of an engineered polyene NPP analogue in Pseudonocardia autotrophica. J. Ind. Microbiol. Biotechnol. 44, 1293-1299. doi: 10.1007/s10295-017-1954-8

Zotchev, S., Haugan, K., Sekurova, O., Sletta, H., Ellingsen, T. E., and Valla, S. (2000). Identification of a gene cluster for antibacterial polyketide derived 
antibiotic biosynthesis in the nystatin producer Streptomyces noursei ATCC 11455. Microbiology 146, 611-619. doi: 10.1099/00221287-146-3-611

Conflict of Interest: The authors declare that the research was conducted in the absence of any commercial or financial relationships that could be construed as a potential conflict of interest.
Copyright (c) 2020 Park, Kim, Han, Nah, Choi and Kim. This is an open-access article distributed under the terms of the Creative Commons Attribution License (CC BY). The use, distribution or reproduction in other forums is permitted, provided the original author(s) and the copyright owner(s) are credited and that the original publication in this journal is cited, in accordance with accepted academic practice. No use, distribution or reproduction is permitted which does not comply with these terms. 